\title{
EFFECT OF STORAGE AND PACKAGING CONDITIONS ON PHYSICAL PROPERTIES AND CAROTENOID CONTENT OF MANGO TABLETS
}

\author{
THORUNG PRANIL ${ }^{1}$, ANUCHITA MOONGNGARM*1, GREEPOL MANWIWATTANAGUL ${ }^{2}$ \\ AND WILLIAM L KERR ${ }^{3}$
}

${ }^{\prime}$ Research Unit of Nutrition for Life, Department of Food Technology and Nutrition, Faculty of Technology, Mahasarakham University, Maha Sarakham 44150, Thailand. ${ }^{2}$ Faculty of Pharmacy, Mahasarakham University, Maha Sarakham 44150, Thailand. ${ }^{3}$ Department of Food Science and Technology, University of Georgia, 100 Cedar Street, Athens, GA 30602-2610, USA.

*Corresponding author: anuchitac@yahoo.co.th

Submitted final draft: 7 September $2020 \quad$ Accepted: 17 October $2020 \quad$ http://doi.org/10.46754/jssm.2021.02.015

\begin{abstract}
Storage conditions play an important role in the physical and chemical stability of food tablets. Mango tablets were prepared and stored under controlled in either polyethylene or laminated plastic bags with relative humidity of $32 \%$ and $75 \%$ at temperatures of 4,25 , and $35^{\circ} \mathrm{C}$ for six months. Moisture content, water activity, carotenoid content, weight, shape, color, and texture were regularly assessed. Both storage conditions and storage time influenced the mango tablet properties. Combination of high temperature $\left(35^{\circ} \mathrm{C}\right)$, high relative humidity $(75 \%)$ and packaging in polyethylene plastic bags significantly increased moisture content and water activity of mango tablets. This led to changes in other properties, including decreased carotenoid content, diameter, thickness, $\mathrm{L}^{*}, \mathrm{~b}^{*}$ and hardness, and also increased weight, $\mathrm{a}^{*}$ and fracturability. No significant changes were observed in tablets packed in laminated plastic bags (non-permeable to oxygen and humidity) irrespective of temperature and relative humidity. Results showed that mango tablet stability was influenced by packaging and storage conditions.
\end{abstract}

Keywords: Stability, mango tablet, temperature, relative humidity, packaging.

\section{Introduction}

Mango (Mangifera indica L., Anacardiaceae) is grown in many parts of the world, especially tropical countries (Jahurul et al., 2015). Thailand was the second-largest exporter of mangoes in 2018 at 257,600 tons, equal to $6.4 \%$ of the total global production (FAO, 2019). Mangoes have a unique flavor and provide dietary fiber, carbohydrates, proteins, essential vitamins, antioxidants and other phytochemicals beneficial for health (Tharanathan et al., 2006). Ripe mangoes are a good source of carotenoids. The rate of total carotenoid accumulation in mangoes is slow during the initial growth stages, but increases as the fruits approach maturity (John et al., 2006). Carotenoids comprise the yellow pigments presented in the peel and pulp. Mangoes contain both carotenes (provitamin A carotenoids) and xanthophylls (Ben-Amotz \& Fishier, 1998; Cano \& de Ancos, 1994; John et al., 2006). Carotenoids have been linked to several biological functions, including provitamin A activity, modulation of detoxifying enzymes, antioxidant activity, enhancement of immune response, apoptosis induction, cell communication and regulating gene expression (Clevidence et al., 2000). Ripe mangoes are also an excellent source of vitamins like riboflavin (vitamin B2), thiamine (vitamin B1) and niacin, while high vitamin $\mathrm{C}$ and folic acid are beneficial for maintaining health (Gopalan et al., 1989; Moore, 2003; Spencer et al., 1956).

However, mangoes are perishable and large quantities are wasted during processing, packing, storage and transportation each year. Therefore, privatization to add value is both important and necessary. Several techniques are currently applied to process mangoes into a variety of products to increase its value and improve shelf life, such as pulping into nectar and juice concentrates, and drying/dehydrating (Ravani \& Joshi, 2013; Siddiq et al., 2017). The mango tablet is an interesting and innovative product that contains bioactive compounds, 
such as carotenoids, fiber and antioxidants, which is similar to that in ripe mangoes. Its light weight makes it convenient to transport and consume. It also has a long shelf life. However, only a few studies have previously investigated the production of mango tablets. Therefore, this study is conducted to develop new products from local fruits i.e. mangoes. The suitable packaging and storage conditions will be investigated.

Here, the influence of various factors on the stability of both physical and chemical properties of mango tablets was examined during storage in polyethylene or laminated plastic bags at different relative humidity (32 and $75 \%$ ) and temperature $\left(4,25\right.$ and $\left.35^{\circ} \mathrm{C}\right)$ for six months. Data obtained can be used as guidelines to predict changes in fruit tablet properties after storage under those conditions.

\section{Materials and Methods}

\section{Raw Materials and Chemicals}

Fresh ripe mangoes (Nam Dok Mai variety) grown in Maha Sarakham province, Thailand, and harvested in May 2018 were purchased from a local market. The tablet ingredients included spray-dried lactose monohydrate (USP grade, SuperTab 14SD, FSD), fumed silica (WackerChemie GmBH, Germany) and magnesium stearate (Cooper, Melun, France).

Chemicals used for maintaining relative humidity conditions were potassium carbonate $\left(\mathrm{K}_{2} \mathrm{CO}_{3}\right.$, Sigma-Aldrich Chemical Co., St. Louis, MO, USA) and sodium chloride ( $\mathrm{NaCl}$, J.T. Baker Chemical Co., Phillipsburg, NJ, USA). Acetone used for carotenoid determination was purchased from a local supplier (RCI Labscan Limited, Bangkok, Thailand).

\section{Preparation of Mango Tablets}

The mangoes were washed thoroughly in tap water and peeled. The fruit was chopped into small pieces, blended using a blender and stored in a $-40^{\circ} \mathrm{C}$ freezer until it lyophilized. Frozen mangoes were placed in a vacuum freeze-dryer
(Heto PowerDry, PL3000, Czech Republic) and dried at $-11^{\circ} \mathrm{C}$ for $48 \mathrm{~h}$ at $0.2 \mathrm{MPa}$ pressure (Ong et al., 2014). Following lyophilization, the dried mangoes were ground using a blender. The grinding process was paused every 30 seconds to avoid excessive heating of the samples. The mango powder was packaged in plastic bags and stored at $-20^{\circ} \mathrm{C}$ as protection from light and moisture.

Mango powder at $70 \%$ was appropriately blended with spray-dried lactose monohydrate $28 \%$, fumed silica $1 \%$, and magnesium stearate $1 \%$ for 30 min using a mixing machine (Saifullah et al., 2014) before being passed through a $150 \mu \mathrm{m}$ sieve. Two grams of the mixture were weighed using a digital balance and placed on a $20 \mathrm{~mm}$ single stainless steel punch tablet press die. Tablets were prepared by direct compression using a single punch tablet compression machine (Shimadzu Corporation, Kyoto, Japan) at a compression force of 5 KiloNewtons. Each tablet was ejected from the die and initially stored at $-20^{\circ} \mathrm{C}$ as protection from light and moisture.

\section{Stability of Mango Tablets}

The tablets were vacuum packaged in polyethylene plastic bags $(100 \mu \mathrm{m}$, clean polypropylene) (Uline, Waukegon, IL, USA) or laminated plastic bags $(100 \mu \mathrm{m}$ PET, 100 $\mu \mathrm{m} \mathrm{Al}, 75 \mu \mathrm{m} \mathrm{PE})$ (HBB; StandUp Pouches, Avon, OH, USA), and stored in two humidity chambers with relative humidity maintained using saturated saline solutions. Potassium carbonate $\left(\mathrm{K}_{2} \mathrm{CO}_{3}\right)$ was used to maintain relative humidity at $43 \pm 5 \%$ and sodium chloride $(\mathrm{NaCl})$ to maintain relative humidity at $75 \pm 5 \%$. The chambers were stored in a refrigerator $\left(4^{\circ} \mathrm{C}\right)$ and two incubator ovens maintained at 25 and $35^{\circ} \mathrm{C}$ under aseptic conditions. Physical and chemical properties of the tablets were measured at 0,1 , 2, 3, 4, 5 and 6 months.

\section{Determination of Mango Tablets Properties}

The properties of the mango tablets were determined as follows: 
1) Measurement of moisture content and water activity $\left(a_{w}\right)$

Moisture content was measured using a moisture analyzer (Mettler-Toledo AG, Greifensee, Switzerland), while water activity $\left(\mathrm{a}_{\mathrm{w}}\right)$ was measured using an Aqualab Series 3 Water Activity Meter (Decagon Devices Inc, Pullman, WA, USA) at room temperature.

\section{2) Determination of total carotenoid}

Carotenoid content in the tablets was determined following the method described by Askar \& Treptow (2013). The tablets were soaked with $85 \%$ acetone and left overnight in a dark place. The extracts were vacuum filtered through a Whatman ${ }^{\circledR}$ No. 1 filter paper (Whatman International Ltd, Maidstone, UK) using a Kitasato flask connected to a Buchner funnel and vacuum pump. Analyses of filtered extracts were carried out using a Thermo Spectronic Genesys 2 Spectrophotometer (Thermo Fisher, Waltham, MA, USA) with wavelength absorbance at 440, 644, and $662 \mathrm{~nm}$.

3) Determination of weight, thickness and diameter

Mango tablets were weighed using a Laboratory Scale Analytical Precision Balance Scale. Thickness and diameter were measured using an ANENG 0-100 $\mathrm{mm}$ LCD digital electronic vernier caliper gauge micrometer carbon fiber.

\section{4) Determination of color}

Color of the mango tablets was measured using a Minolta Chroma Meter CR-300 (Konica Minolta, Chiyoda, Japan). Results were expressed as Hunter color values of $\mathrm{L}^{*}, a^{*}$, and $b^{*}$. The $\mathrm{L}^{*}$ represents lightness $\left(\mathrm{L}^{*}=0\right.$ yields black and $\mathrm{L}^{*}=100$ indicates diffuse white). The Chroma $\left(\mathrm{C}^{*}\right)$ represents color intensity, which is the distance of color from the origin $\left(a^{*}=b^{*}=0\right)$ in $a^{*}$ and $b^{*}$ planes. Hue angle $\left(\mathrm{h}^{\circ}\right)$ expressed in degrees ranges from $0^{\circ}$ to $360^{\circ}$, where $0^{\circ}$ (red) is located on the $+a^{*}$ axis, then rotating anticlockwise to $90^{\circ}$ (yellow) for the $+b^{*}$ axis, $180^{\circ}$ (green) for $-a^{*}$ and $270^{\circ}$ (blue) for $-b^{*}$. The formula for measuring the difference in color is expressed in Equation 1.

$\Delta E=\sqrt{\left(L_{1}-L_{0}\right)^{2}+\left(a_{1}-a_{0}\right)^{2}+\left(b_{1}-b_{0}\right)^{2}}$ (Eq. 1)

\section{5) Determination of hardness and fracturability}

Hardness and fracturability of tablets for each formulation were determined using a TA-XT2 texture analyzer (Stable Micro Systems Co., Ltd., Godalming, Surrey, UK) with a $3 \mathrm{~mm}$ cylinder probe. Test samples were measured using the following settings: pre-test speed, $1 \mathrm{~mm} / \mathrm{s}$; test speed, $1 \mathrm{~mm} / \mathrm{s}$; and, post-test speed, $10 \mathrm{~mm} / \mathrm{s}$, all under a trigger force of $50 \mathrm{~g}$.

\section{Statistical Analysis}

All experiments were performed in triplicates. IBM SPSS version 24 (IBM Corp, Armonk, NY, USA) was employed for data analyses. Statistical significance was declared at $\mathrm{P}<0.05$.

\section{Results and Discussion}

Stability of the physical and chemical properties of mango tablets depended on several parameters, including environmental conditions (oxygen, light, temperature and humidity).

Figure 1 shows the mango tablet color and shape after storage under different conditions. Mango tablets kept in laminated plastic bags under all conditions (varied temperature and relative humidity) were relatively stable during storage for six months. Packaging was the main factor influencing changes in tablet qualities, while both temperature and relative humidity also affected tablet property changes. Mango tablets kept in polyethylene plastic bags stored at high temperature $\left(35^{\circ} \mathrm{C}\right)$ and relative humidity (75\%) were observed to have the biggest change in physical characteristics. The color turned from light yellow to almost black, while the shape was altered from round to shapeless. 
Most of the tablets stored in polyethylene bags at room temperature and above would also experience some form of discoloration within the first month of storage regardless of relative humidity. A lower temperature at $4^{\circ} \mathrm{C}$ could be seen slowing down the discoloration to three months.

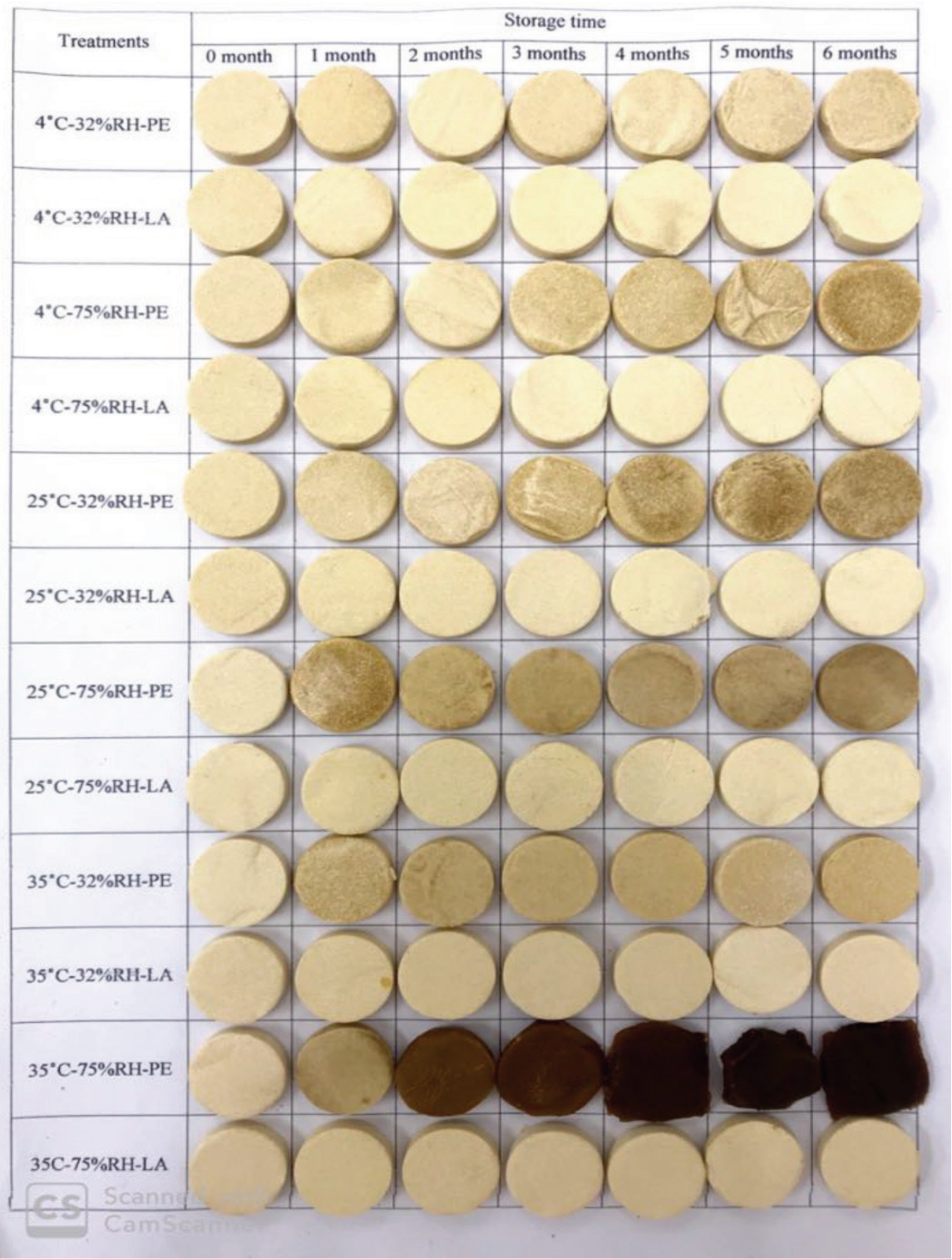

Figure 1: Physical properties of mango tablets during storage at different temperatures $\left(4,25\right.$ and $\left.35^{\circ} \mathrm{C}\right)$, relative humidity ( $32 \%$ and $75 \% \mathrm{RH})$ and in polyethylene (PE) or laminated (LA) plastic bags 
Effect of Storage Conditions on Moisture Content and Water Activity of Mango Tablets

Figures 2 presents the effect of storage conditions on water activity and moisture content of mango tablets. Water activity and moisture content increased significantly with increase in storage period $(\mathrm{P}<0.05)$, which were observed in other studies (Khan, 1981; Yu et al., 2011). The $\mathrm{a}_{\mathrm{w}}$ values of mango tablets stored in polyethylene bags at relative humidity of $75 \%$ and temperatures 4,25 and $35^{\circ} \mathrm{C}$ increased from 0.18 to $0.34,0.66$ and 0.68 , respectively, while moisture content increased from 1.66 to $4.67,8.88$ and 11.65 , respectively, after more than six months The levels of water activity and moisture content during storage of fruit tablets at pharmaceutical dosage were recommended between 0.3 to 0.4 , and 2 to $10 \%$, respectively (Nokhodchi, 2005; Srikusalanukul et al., 2007; Cundell, 2015). Therefore, at higher temperatures of 25 and $35^{\circ} \mathrm{C}$, water activity and moisture content in mango tablets had increased beyong the permissible range, which might promote the growth of mold and bacteria. - For storage in laminated plastic under the same conditions, water activity increased from 0.18 to $0.26,0.25$ and 0.25 at 4,25 and $35^{\circ} \mathrm{C}$, respectively, while moisture content increased from 1.66 to $2.7,2.65$ and 2.97. These values were within the permissible range and the tablets stored in laminated plastic showed no deterioration.

Constant change in water activity and moisture content of mango tablets in both packaging materials occurred as a result of the water vapor permeability of the packaging material. Generally, moisture contents of samples stored in polyethylene bags, irrespective of relative humidity and storage temperature, were higher than samples stored in laminated bags. Polyethylene bags were made from 100 $\mu \mathrm{m}$ clean polyethylene resin with good clarity and fair gas barriers, while laminated plastic bags were manufactured from $100 \mu \mathrm{m}$ PET, 100 $\mu \mathrm{m} \mathrm{Al}$ and $75 \mu \mathrm{m}$ PE. This complex packaging material provided the best protection under all storage conditions with excellent oxygen barrier properties.

Results indicated that tablets stored at 32\% relative humidity showed a slight increase in water activity and moisture content, while tablets kept at $75 \%$ relative humidity experienced a pronounced increase, especially under storage at high temperatures of 25 and $35^{\circ} \mathrm{C}$. These differences can be explained because, at high relative humidity, the concentration of water vapour in air is more saturated. Therefore, the tablets would absorb more water (Kuu et al., 1998; Nokhodchi, 2005; Srikusalanukul et al., 2007; Cundell, 2015). At higher temperature, the water molecules in the atmosphere had more energy and moved faster than at lower temperature (Yu et al., 2011). Therefore, chemical reactions, i.e., water absorption, were typically expected to proceed faster at higher temperatures (Vaccarezza et al., 1974). These results concurred with Li and Peck (1990) and Powers and Calvo (2003). who reported that the two most influential environmental factors affecting moisture content in a product were temperature and relative humidity. Moreover, mango tablets stored for more than six months had water activity of no more than $0.7 \%$. This result could be because the water activity in the tablets had reached equilibrium with relative humidity inside the controlled chamber (Alwan, 2013). 


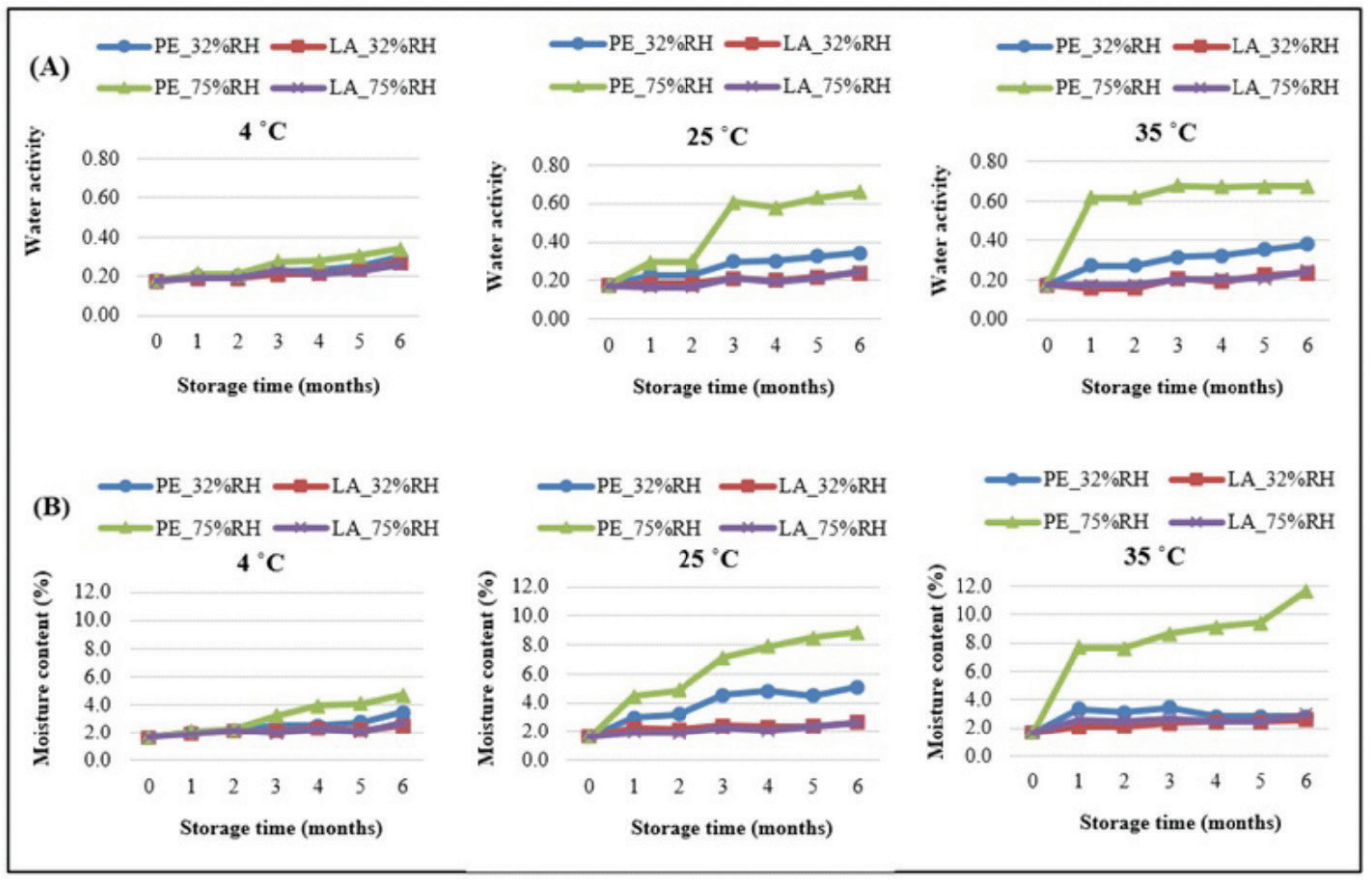

Figure 2: Changes in water activity (A) and moisture content (B) of mango tablets during storage under different temperatures, relative humidity $(\mathrm{RH})$, polyethylene bags (PE) and laminated bags (LA)

\section{Effect of Different Storage Conditions on Carotenoid Content of Mango Tablets}

Processing of mango products could significantly degrade the carotenoid content. For instance, freeze-dried mango contained a high quantity of total carotenoids $(5.2 \mathrm{mg} / 100 \mathrm{~g} \mathrm{db})$ than dried mango prepared from three drying techniques (Sogi, Siddiq, \& Dolan, 2015). Besides, storage conditions also played a significant role in the remaining total carotenoids in dried mango products.

Figure 3 shows the effect of temperature, relative humidity and packaging on carotenoid content in the tablets. Carotenoid content of tablets kept in the refrigerator $\left(4^{\circ} \mathrm{C}\right)$ remained unchanged compared with the initial concentration of $3.34 \mathrm{mg} / 100 \mathrm{~g} \mathrm{db}$, whereas the remaining carotenoid levels after storage ranged from 2.64 to $3.03 \mathrm{mg} / 100 \mathrm{~g} \mathrm{db}$ at $32 \%$ and $75 \%$ relative humidity. On the other hand, the amount of carotenoid in mango tablets decreased to 1.06 and $1.02 \mathrm{mg} / 100 \mathrm{~g} \mathrm{db}$ when stored at $25^{\circ} \mathrm{C}$ and $35^{\circ} \mathrm{C}$ (Figure $3 \mathrm{~B}$ and $3 \mathrm{C}$ ), respectively, due to the thermal degradation of carotenoid by oxidizing agents. Boon, et al. (2010) reported that oxidizing agents could induced oxidation pathways that degraded the carotenoid at its conjugated polyene chain.

Marty \& Berset (1990) observed that carotenoids could converted to oxidation products at $180^{\circ} \mathrm{C}$ and, at a higher temperature $\left(240^{\circ} \mathrm{C}\right)$, products such as toluene, m-xylene, p-xylene, ionene, and 2,6-dimethylnaphthalene were also formed (Mader, 1964). Furthermore, thermal treatment of carotenoids in the presence of oxygen could produce 5,6-epoxy $\beta$-carotene, which were converted to various products during heating time of three hours (Kanasawud \& Crouzet, 1990). This result was consistent with El-Tinay \& Chichester (1970), who reported that oxygen treatment at low temperature $\left(60^{\circ} \mathrm{C}\right)$ would break the $\beta$-carotene terminal double bonds and produce various epoxides together with a complex mixture of products. These oxidizing agents converted carotenoid to various radical species that formed peroxyl radicals by reacting with oxygen (Handelman et al., 1991). 
Figure 3B shows the effect of relative humidity on carotenoid stability. Mango tablets kept in laminated bags and stored at 75\% and $32 \%$ relative humidity showed similar carotenoids remaining (1.89-2.08 mg/100 g db). Conversely, tablets kept in polyethylene bags showed different concentrations of remaining carotenoids (1.06-1.44 mg/100 g db). This finding was similar to the stable results of water activity and moisture content for tablets stored in laminated bags. By contrast, tablets stored in polyethylene bags absorbed more water during storage at different relative humidities.

Consequently, relative humidity was strongly associated with the degradation rate of carotenoid in mango tablets. The moisture content in the tablets were the cause of carotenoid oxidation during storage. These results supported previous studies suggesting that low relative humidity storage conditions could reduce carotenoid degradation in maize kernels (Ortiz et al., 2016). Similar results were obtained by Lavelli et al. (2007) at $40^{\circ} \mathrm{C}$. The equilibrium moisture, water activity, $\alpha$ - and $\beta$-carotene, and lutein contents were analysed at different storage times. The Guggenheim-Anderson-de Boer (GAB, who found that stability of $\beta$-carotene increased with decreasing water activity. Bechoff et al. (2010) also reported that higher water activity resulted in lower stability of $\beta$-carotene in dried sweet potato chips during storage. These results showed the significant effect of relative humidity on stability of carotenoids during storage.

At $35^{\circ} \mathrm{C}$, degradation of carotenoids in mango tablets demonstrated two rates. Higher degradation rates were encountered in tablets kept in polyethylene bags and stored at $75 \%$ and $32 \%$ relative humidity. Remaining carotenoid contents were 1.02 and $1.33 \mathrm{mg} / 100$ $\mathrm{g} \mathrm{db}$, respectively, from an initial concentration of $3.34 \mathrm{mg} / 100 \mathrm{~g} \mathrm{db}$. On the contrary, tablets kept in laminated bags showed slower degradation rate with remaining carotenoid contents at more than $1.7 \mathrm{mg} / 100 \mathrm{~g} \mathrm{db}$, indicating that the packaging material played an integral part in protecting the tablets from environmental conditions (Sabah et al., 2014). Tablets kept in polyethylene bags had absorbed more moisture than those in laminated bags.

The absorbed moisture significantly affected the degradation rate of carotenoids, while acceptable packaging not only protected tablets from moisture but also prevented ingress of oxygen, light and acid.

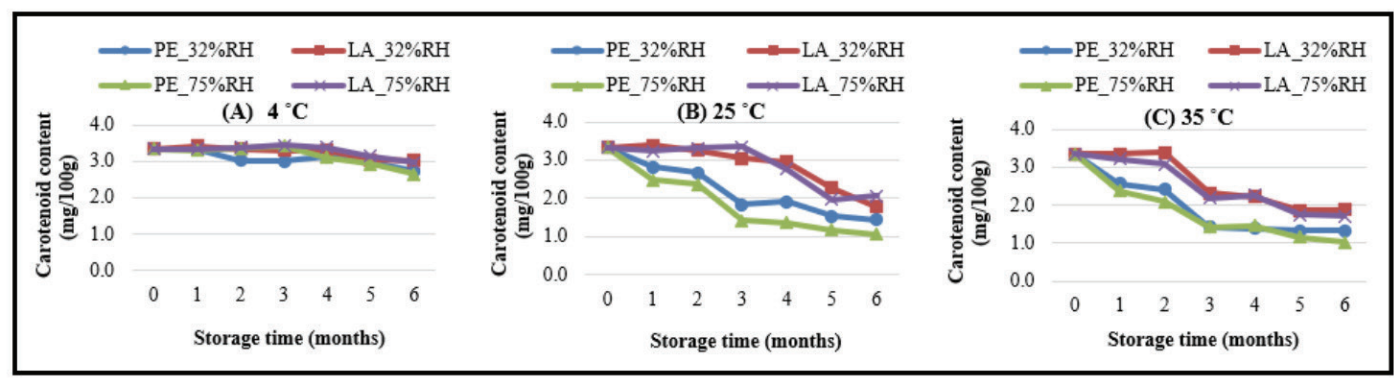

Figure 3: Changes in carotenoid content of mango tablets during storage under different temperatures, relative humidity $(\mathrm{RH})$ and in polyethylene (PE) or laminated (LA) bags 
Effect of Different Storage Conditions on Weight, Diameter and Thickness of Mango Tablets

Weight, diameter and thickness of the mango tablets are shown in Figure 4. Weight of the mango tablets increased gradually during prolonged storage due to higher moisture absorption (Ezealisiji et al., 2016), whereas diameter and thickness slightly decreased. At the molecular level, this occurred because cellulose fibers in the tablet had absorbed moisture that promoted the movement of the internal polymer chains through lubrication, which disrupted the hydrogen bonding between the polymer chains. When the cellulose fibers were stressed, the internal polymer chains would move to relieve the stress. Consequently, hydrogen bonds in the polymer chains would reform into a new configuration. Moreover, the new wrinkled form would remain until restoring forces corrected it to its original configuration. Therefore, moisture absorption facilitated swelling of the cellulose fibers, and this resulted in tablet shrinkage (Roy Choudhury, 2017).

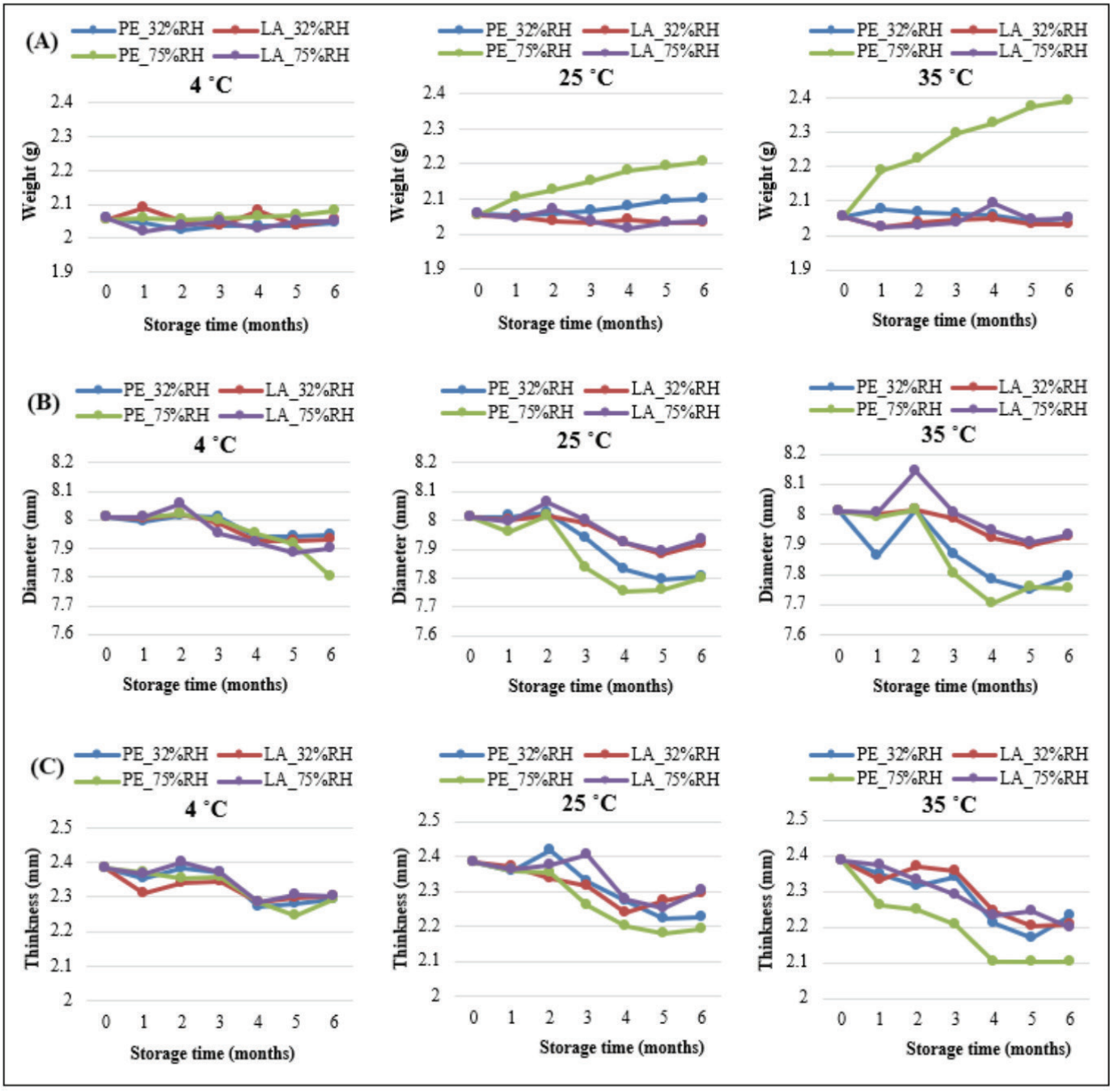

Figure 4: Changes in weight, diameter and thickness of mango tablets during storage under different temperatures, relative humidity $(\mathrm{RH})$ and in polyethylene (PE) or laminated (LA) bags 
Effect of Different Storage Conditions on Hardness and Fracturability of Mango Tablets

Textural properties of the mango tablets, including hardness and fracturability, were determined using a texture analyzer. Hardness was defined as the amount of force required to compress the food completely, while fracturability encompassed crumbliness, crispiness, crunchiness and brittleness as the characteristics in breaking or crushing the food (Paula \& Conti-Silva, 2014). Hardness and fracturability change in mango tablets during the storage period are presented in Figure 5.

The hardness value was directly related to moisture content. Lower moisture content at $4-5 \%$ resulted in harder tablets. By contrast, at higher moisture content $(5-12 \%)$, a significant decrease in hardness was observed. Moisture dissolved on the tablet surface would lead to viscoelastic properties that cause powerful interactions between particles in the tablet. Initially, the particles in the tablets were bound together by Van der Waals force and formation of hydrogen bonds (Nokhodchi et al., 1995). However, as moisture content increased (5-
$12 \%$ ), multiple layers of the tablet surface would absorb the water and this disrupted the bonds between particles by increasing elastic recovery and decreasing hydrodynamic resistance (Khan, 1981; Li \& Peck, 1990; Malamataris, 1991; Nokhodchi et al., 1995; Thapa et al., 2017), resulting in decreased hardness value of the tablet.

Similar results were also observed in mango tablet fracturability. Changes in tablet fracturability were influenced mainly by moisture content. The presence of excessive moisture increased the fracturability value of mango tablets since excessive moisture also increased its softness. Hence, more force was required to crush the tablets into powder (Abbott, 1973; Paula \& Conti-Silva, 2014). Similar results were observed in many studies, such as Sasiophat (2016), which studied the effects of using dried fruit on the physical qualities of fried pumpkins. The author found that the reduction of moisture in pumpkin slices was well related to the decline of hardness and fracturability value. The effect of moisture content on fracturability and hardness was also found in extruded oat-corn Puff (Liu et al., 2000).

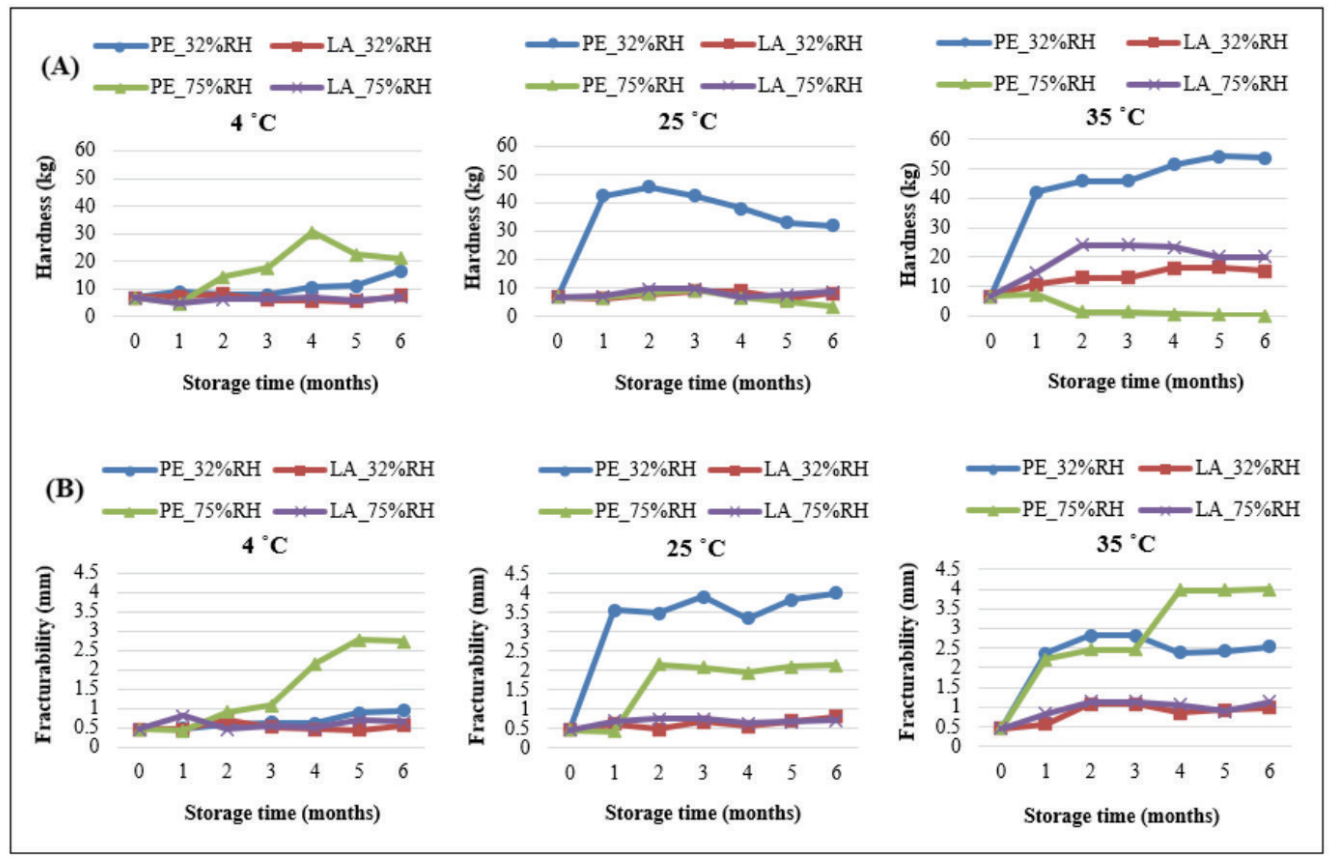

Figure 5: Changes in texture of mango tablets during storage under different temperatures, relative humidity $(\mathrm{RH})$ and in polyethylene (PE) or laminated (LA) bags 
Effect of Different Storage Temperatures on Color of Mango Tablets

Color parameters $\left(\mathrm{L}^{*}, \mathrm{a}^{*}\right.$ and $\left.\mathrm{b}^{*}\right)$ and progress of color change $(\Delta \mathrm{E})$ of mango tablets kept in different packaging and stored at different relative humidities and temperatures are illustrated in Figure 6. Tablets kept in polyethylene bags at higher relative humidity and temperature for a longer time resulted in increasing $\mathrm{a}^{*}$, decreasing $\mathrm{L}^{*}$ and $\mathrm{b}^{*}$ and, eventually, higher $\Delta \mathrm{E}$. The process of food turning brown is related to the non-enzymatic reaction between an amino acid and a reducing sugar, also known as the Maillard reaction. This chemical reaction depends on processing conditions such as temperature and water activity. For these reasons, changes in $\mathrm{L}^{*}$, $a^{*}$, and $b^{*}$ values were seen at high temperature and relative humidity conditions for tablets kept in polyethylene bags that promoted water absorption. The Maillard reaction occurs in food at water activities between 0.5 and 0.8 (Jeantet et al., 2016). At high temperature and relative humidity, water activity values of mango tablets kept in polyethylene bags were mostly higher than 0.5 , while values for mango tablets kept in laminated bags were less than 0.25 . Due to limited water vapor and oxygen transmission rates, the Maillard reaction rate was lower for mango tablets kept in laminated bags.

Data indicated that at low temperature, both polyethylene and laminated bags could be used as only minimal change occurred in all physical properties and carotenoid content. However, for tablets stored at higher temperature (25 and $\left.35^{\circ} \mathrm{C}\right)$ and high relative humidity $(75 \%)$, polyethylene bags were not suitable due to faster absorption of moisture that affected changes in size, color and texture. For these reasons, laminated containers offered better protection for storage under conditions of high temperature and relative humidity. These showed no significant change in physical properties of the tablet under different storage conditions.

\section{Conclusions}

The results indicated that different storage conditions (packaging, relative humidity and temperature) and long-term storage affected both physical and chemical qualities of mango tablets. Critical parameters influencing physical properties of mango tablets were moisture content and water activity. These had direct effects on color and texture. Packaging was also a key factor as material properties related to water vapor transmission rates and water absorption of the tablets were directly affected by other physical and chemical qualities.

\section{Acknowledgement}

This research was funded by the Thailand Research Fund (TRF; The Royal Golden Jubilee Ph.D. Programme [PHD/0113/2558]) and Mahasarakham University, Thailand [6203001/2562]. 


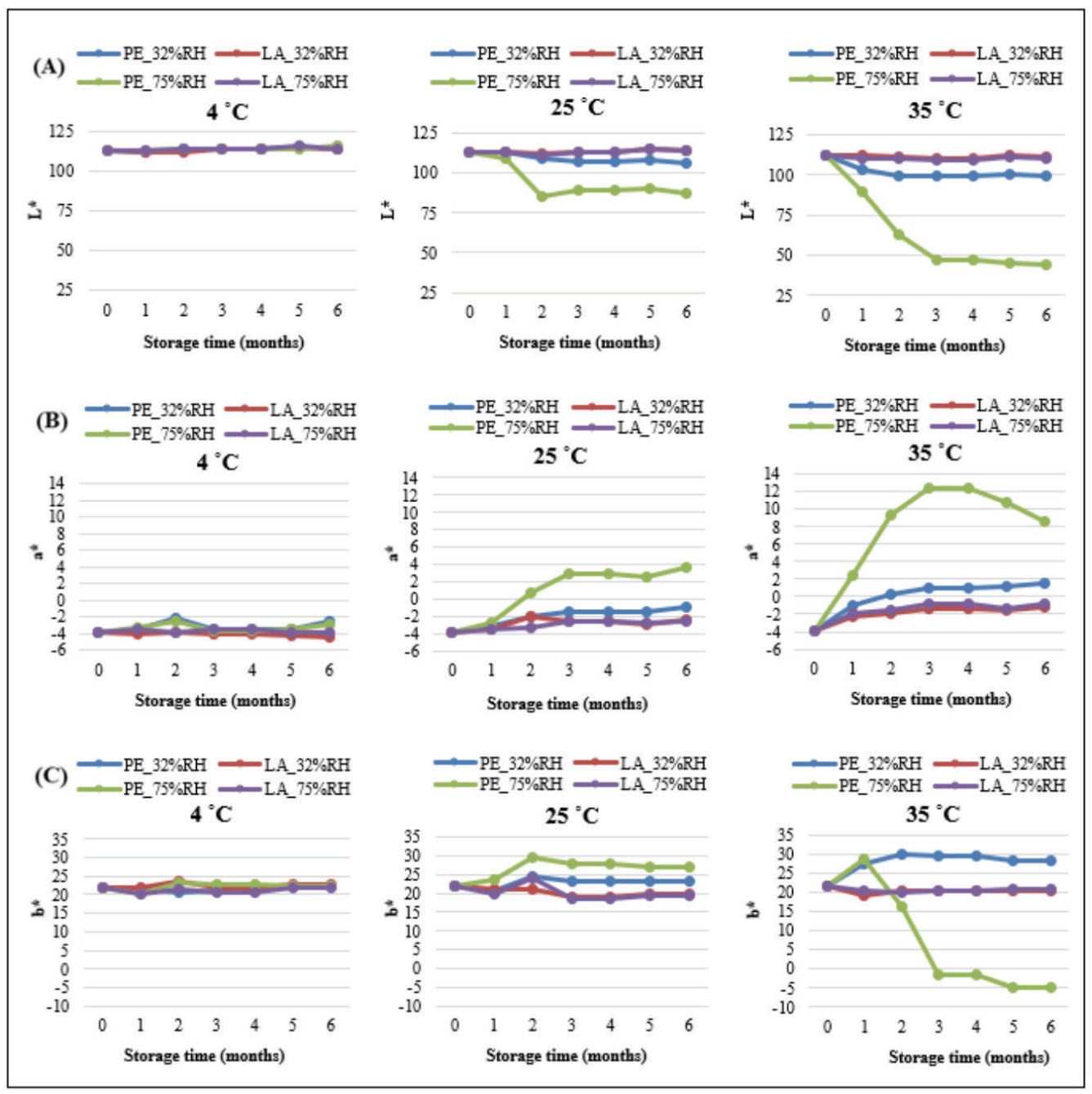

Figure 6: Changes in the color of mango tablets during storage under different temperatures, relative humidity $(\mathrm{RH})$ and in polyethylene (PE) or laminated (LA) bag

\section{References}

Abbott, J. A. (1973). Sensory Assessment of Textural Attributes of Foods. In Amihud Kramer \& A. S. Szczesniak (Eds.), Texture Measurements of Foods (pp. 1732). Springer, Dordrecht. https://doi. org/10.1007/978-94-010-2562-1_3.

Alwan, M. M. (2013). Equilibrium Moisture Sorption Isotherms of Aspirin. Journal of Engineering, 19(4), 453-464.
Askar, A., \& Treptow, H. (2013). Quality assurance in tropical fruit processing (pp. 30-33). Springer Science \& Business Media.

Bechoff, A., Dhuique-Mayer, C., Dornier, M., Tomlins, K. I., Boulanger, R., Dufour, D., $\&$ Westby, A. (2010). Relationship between the kinetics of $\beta$-carotene degradation and formation of norisoprenoids in the storage of dried sweet potato chips. Food Chemistry, 121(2), 348-357. https://doi. org/10.1016/j.foodchem.2009.12.035. 
Ben-Amotz, A., \& Fishier, R. (1998). Analysis of carotenoids with emphasis on 9-cis $\beta$-carotene in vegetables and fruits commonly consumed in Israel. Food Chemistry, 62(4), 515-520. https:// doi.org/https://doi.org/10.1016/S03088146(97)00196-9.

Boon, C. S., McClements, D. J., Weiss, J., \& Decker, E. A. (2010). Factors influencing the chemical stability of carotenoids in foods. Critical Reviews in Food Science and Nutrition, 50(6), 515-532. https://doi. org/10.1080/10408390802565889.

Cano, M. P., \& de Ancos, B. (1994). Carotenoid and Carotenoid Ester Composition in Mango Fruit as Influenced by Processing Method. Journal of Agricultural and Food Chemistry, 42(12), 2737-2742. https://doi. org/10.1021/jf00048a017.

Clevidence, B., Paetau, I., \& Smith, J. C. (2000). Bioavailability of carotenoids from vegetables versus supplements. Vegetables, Fruits, and Herbs in Health Promotion, 35(May 1999), 19-34. https:// doi.org/10.1201/9781420042542.ch2.

Cundell, T. (2015). The role of water activity in the microbial stability of non-sterile drug products. European Pharmaceutical Review, 20, 58-63.

El-Tinay, A. H., \& Chichester, C. O. (1970). Oxidation of $\beta$-Carotene. Site of Initial Attack. Journal of Organic Chemistry, 35(7), 2290-2293. https://doi.org/10.1021/ jo00832a040.

Ezealisiji, K., Pepple, A., \& Stanley, C. (2016). Effect of Sunlight, Moisture, Temperature and Ultraviolet Radiation on the Quality Control Parameters of Ciprofloxacin Tablet Formulation. International Journal of Drug Delivery, 8(3), 99. https://doi. org/10.5138/09750215.1928.

FAO. (2019). Major tropical fruits - Statistical compendium 2018. https://doi.org/10.4060/ ca5688en.
Feng, X., Wang, M., Zhao, Y., Han, P., \& Dai, Y. (2014). Melatonin from different fruit sources, functional roles, and analytical methods. Trends in Food Science and Technology, 37(1), 21-31. https://doi. org/10.1016/j.tifs.2014.02.001.

Gopalan, C., Sastri, B. V. R., \& Balasubramanian, S. C. (1989). Nutritive Value of Indian Foods (pp. 45-91). National Institute of Nutrition, Indian Council of Medical Research. Retrieved from https://books. google.co.th/books?id=biFBAAAAYAAJ.

Handelman, G. J., van Kuijk, F. J. G. M., Chatterjee, A., \& Krinsky, N. I. (1991). Characterization of products formed during the autoxidation of $\beta$-carotene. Free Radical Biology and Medicine. https://doi. org/10.1016/0891-5849(91)90051-4.

Jahurul, M. H. A., Zaidul, I. S. M., Ghafoor, K., Al-Juhaimi, F. Y., Nyam, K. L., Norulaini, N. A. N., ... Mohd Omar, A. K. (2015). Mango (Mangifera indica L.) by-products and their valuable components: A review. Food Chemistry, 183, 173-180. https://doi. org/10.1016/j.foodchem.2015.03.046

Jeantet, R., Croguennec, T., Schuck, P., \& Brulé, G. (2016). Non-Enzymatic Browning. Handbook of Food Science and Technology, 1, 133-157.

John, J., Subbarayan, C., \& Cama, H. (2006). Carotenoids in 3 stages of ripening of mango. Journal of Food Science, 35, 262-265. https://doi.org/10.1111/j.1365-2621.1970. tb12156.x.

Kanasawud, P., \& Crouzet, J. C. (1990). Mechanism of formation of volatile compounds by thermal degradation of carotenoids in aqueous medium. 1. $\quad \beta$-Carotene degradation. Journal of Agricultural and Food Chemistry, 38(1), 237-243. https://doi.org/10.1021/ jf00091a052.

Khan, K.A., P. flusikabhumma dr J. P. W. (1981). The Effect of Moisture Content of Microcrystalline Cellulose on the 
Compressional Properties of Some Formulations. Drug Development and Industrial Pharmacy, 7(5), 525-538. https:// doi.org/10.3109/03639048109057729.

Kuu, W. Y., Chilamkurti, R., \& Chen, C. (1998). Effect of relative humidity and temperature on moisture sorption and stability of sodium bicarbonate powder. International Journal of Pharmaceutics, 166(2), 167-175. https:// doi.org/10.1016/S0378-5173(98)00049-0.

Lavelli, V., Zanoni, B., \& Zaniboni, A. (2007). Effect of water activity on carotenoid degradation in dehydrated carrots. Food Chemistry, 104(4), 1705-1711. https://doi. org/10.1016/j.foodchem.2007.03.033.

Li, L. C., \& Peck, G. E. (1990). The effect of moisture content on the compression properties of maltodextrins. Journal of Pharmacy and Pharmacology, 42(4), 272-275. https://doi. org/10.1111/j.2042-7158.1990.tb05406.x

Liu, Y., Hsieh, F., Heymann, H., \& Huff, H. E. (2000). Effect of process conditions on the physical and sensory properties of extruded oat-corn puff. Journal of Food Science, 65(7), 1253-1259. https://doi. org/10.1111/j.1365-2621.2000.tb10274.x

Mader, L. (1964). Beta-Carotene: Thermal Degradation. Science (New York, N.Y.), 144(0), 533-534. https://doi.org/10.1126/ science.144.3618.533.

Malamataris, S., Goidas, P., \& Dimitriou, A. (1991). Moisture sorption and tensile strength of some tableted direct compression excipients. International Journal of Pharmaceutics, 68(1-3), 51-60. https://doi. org/10.1016/0378-5173(91)90126-9.

Marty, C., \& Berset, C. (1990). Factors Affecting the Thermal Degradation of all-trans- $\beta$ Carotene. Journal of Agricultural and Food Chemistry, 38(4), 1063-1067. https://doi. org/10.1021/jf00094a033.

Moore, J. P. (2003). Carotenoid Synthesis and Retention in Mango (Mangifera Indica) Fruit and Puree as Influenced by
Postharvest and Processing Treatments (Master's thesis) (pp. 1-8). University of Florida, Florida, The United States.

Nokhodchi, A., Rubinstein, M. H., Larhrib, H., \& Guyot, J. C. (1995). The effect of moisture on the properties of ibuprofen tablets. International Journal of Pharmaceutics, 118(2), 191-197. https:// doi.org/10.1016/0378-5173(94)00354-8.

Nokhodchi, A. (2005). An overview of the effect of moisture on compaction and compression. Pharmaceutical Technology, 29(1), 46-66.

Ortiz, D., Rocheford, T., \& Ferruzzi, M. G. (2016). Influence of Temperature and Humidity on the Stability of Carotenoids in Biofortified Maize (Zea mays L.) Genotypes during Controlled Postharvest Storage. Journal of Agricultural and Food Chemistry (Vol. 64). https://doi. org/10.1021/acs.jafc.5b05698.

Paula, A. M., \& Conti-Silva, A. C. (2014). Texture profile and correlation between sensory and instrumental analyses on extruded snacks. Journal of Food Engineering, 121(1), 9-14. https://doi. org/10.1016/j.jfoodeng.2013.08.007.

Powers, T. H., \& Calvo, W. J. (2003). Moisture regulation. Novel Food Packaging Techniques, 172-185. https://doi. org/10.1016/B978-1-85573-675-7.500134.

Roy-Choudhury, A. K. (2017). Easy-care finishing. Principles of Textile Finishing (pp. 252-253). https://doi.org/10.1016/ b978-0-08-100646-7.00009-6.

Sabah, D., Ahmed, I., Aa, A., Arif, A., Tanwir, S., Naqvi, A., \& Ahmed, F. (2014). Features, Functions and Selection of Pharmaceutical Packaging materials. International Journal of Pharmaceuticals and Neutraceuticals Research, 1(1), 1-12.

Sasiophat, N. (2016). Effects of initial moisture influencing the physical quality of fried 
pumpkins. Science and Technology RMUTT Journal, 6(2), 157-165.

Sogi, D. S., Siddiq, M., \& Dolan, K. D. (2015). Total phenolics, carotenoids and antioxidant properties of Tommy Atkin mango cubes as affected by drying techniques. LWT - Food Science and Technology, 62(1), 564-568. https://doi.org/10.1016/j.lwt.2014.04.015

Spencer, J. L., Morris, M. P., \& Kennard, W. C. (1956). Vitamin C Concentration in Developing and Mature Fruits of Mango (Mangifera indica L.). Plant Physiology, 31(1), 79-80. https://doi.org/10.1104/ pp.31.1.79.

Srikusalanukul, A., Hutangura, P., \& Thumthanaruk, B. (2007). Development of Ingredient Ratios in Corn Milk Tablet Product for Nutritional Value Added. Agricultural Science Journal, 38(6), 107110.

Thapa, P., Lee, A. R., Choi, D. H., \& Jeong, S. H. (2017). Effects of moisture content and compression pressure of various deforming granules on the physical properties of tablets. Powder Technology, 310(March), 92-102. https://doi.org/10.1016/j.powtec. 2017.01 .021

Tharanathan, R. N., Yashoda, H. M., \& Prabha, T. N. (2006). Mango (Mangifera indica L.), "the king of fruits" - An overview. Food Reviews International (Vol. 22). https://doi. org/10.1080/87559120600574493.

Vaccarezza, L. M., Lombardi, J. L., \& Chirife, J. (1974). Kinetics of moisture movement during air drying of sugar beet root. International Journal of Food Science \& Technology, 9(3), 317-327. https://doi. org/10.1111/j.1365-2621.1974.tb01779.x.

Yu, Y. J., Hearon, K., Wilson, T. S., \& Maitland, D. J. (2011). The effect of moisture absorption on the physical properties of polyurethane shape memory polymer foams. Smart Materials and Structures, 20(8). https://doi.org/10.1088/0964-1726/ 20/8/085010. 